\title{
Nutritional status does not explain the increase of carotenoid-based coloration associated with age in Great Tits Parus major
}

\author{
Giraudeau, Mathieu ; Barcelo, Margarida ; Senar, Juan Carlos
}

\begin{abstract}
In many bird species, yearling individuals are less colorful than older ones. However, the causal factors behind this difference of color are for the moment unknown. Here, we used ptilochronology in Great Tits Parus major to assess how nutritional conditions experienced by the same birds as yearling and adult are associated with this increase of coloration. Nutritional status was not different between yearling and adult individuals, suggesting that the increase in coloration with age is not due to an increase in foraging efficiency with age. Instead, our study implicates other behavioral and/or ecophysiological factors that drive yearling/adult differences in carotenoid ornamentation.
\end{abstract}

DOI: https://doi.org/10.1007/s10336-014-1079-z

Posted at the Zurich Open Repository and Archive, University of Zurich ZORA URL: https://doi.org/10.5167/uzh-171991

Journal Article

Published Version

Originally published at:

Giraudeau, Mathieu; Barcelo, Margarida; Senar, Juan Carlos (2014). Nutritional status does not explain the increase of carotenoid-based coloration associated with age in Great Tits Parus major. Journal of Ornithology, 155(4):1063-1066.

DOI: https://doi.org/10.1007/s10336-014-1079-z 


\title{
Nutritional status does not explain the increase of carotenoid- based coloration associated with age in Great Tits Parus major
}

\author{
Mathieu Giraudeau • Margarida Barcelo • \\ Juan Carlos Senar
}

Received: 13 January 2014/Revised: 13 March 2014/ Accepted: 23 April 2014/Published online: 29 May 2014

(C) Dt. Ornithologen-Gesellschaft e.V. 2014

\begin{abstract}
In many bird species, yearling individuals are less colorful than older ones. However, the causal factors behind this difference of color are for the moment unknown. Here, we used ptilochronology in Great Tits Parus major to assess how nutritional conditions experienced by the same birds as yearling and adult are associated with this increase of coloration. Nutritional status was not different between yearling and adult individuals, suggesting that the increase in coloration with age is not due to an increase in foraging efficiency with age. Instead, our study implicates other behavioral and/or ecophysiological factors that drive yearling/adult differences in carotenoid ornamentation.
\end{abstract}

Keywords Growth bars · Great Tit · Carotenoid-based coloration $\cdot$ Nutritional status

\section{Zusammenfassung}

Der Ernährungszustand erklärt nicht die altersbedingte Zunahme in der Karotinoidfärbung bei Kohlmeisen Parus major

Bei vielen Vogelarten sind vorjährige Individuen aufgrund einer altersbedingten Zunahme in der Färbung weniger bunt als ältere. Allerdings sind die diesen Farbunterschieden

Communicated by L. Fusani.

M. Giraudeau ( $\square)$

Institute of Evolutionary Biology and Environmental Studies, University of Zurich, Zurich, Switzerland

e-mail: giraudeau.mathieu@gmail.com

M. Barcelo - J. C. Senar

Behavioural and Evolutionary Ecology Associate Research Unit, CSIC, Natural History Museum of Barcelona, 08003 Barcelona, Spain zugrunde liegenden Faktoren derzeit noch unbekannt. Um diese Wissenslücke zu schließen, führten wir eine Längsschnittsstudie an Kohlmeisen (Parus major) durch, bei der wir anhand des Wachstumsverlaufs (Ptilochronologie) der Steuerfedern abzuschätzen versuchten, inwieweit die von ein und demselben Vogel im Verlauf des Federwachstums durchlebten Ernährungsbedingungen als vorjähriges und später als adultes Tier mit der bei adulten Individuen beobachteten Zunahme der Färbung im Zusammenhang stehen. Es zeigte sich, dass der Ernährungszustand der vorjährigen Vögel sich nicht signifikant von dem der Adulten unterschied, was stark dafür spricht, dass die Zunahme der durch Karotinoide bedingten Gefiederfärbung nicht auf einen generellen altersbedingten Anstieg der Effizienz bei der Nahrungssuche zurückgeführt werden kann. Stattdessen legt unsere Studie nahe, dass andere verhaltensabhängige und/oder ökophysiologische Faktoren die Unterschiede in der Karotinoidfärbung zwischen Vorjährigen und Adulten verursachen.

\section{Introduction}

In many bird species harboring structural or carotenoidbased coloration, yearling individuals are less colorful than older ones (Delhey and Kempenaers 2006; Del Val et al. 2010). This phenomenon can be explained by two nonmutually exclusive processes: a within-individual increase of coloration with age (Delhey and Kempenaers 2006; Del Val et al. 2010) and/or a lower survival rate of less colorful individuals (Pagani-Nuñez and Senar 2012). Using repeated measurements on the same individuals in a multi-year study, Del Val et al. (2010) have recently shown that a within-individual increase of carotenoid-based coloration 
drives the difference of coloration observed between adult and yearling individuals in Great Tits Parus major. However, the causal factor(s) behind this increase of coloration with age are for the moment unknown. Among the factors that may drive this increase of coloration in adult individuals, the nutritional condition appears to be one of the most important since the carotenoid-based coloration have been shown to be a reliable indicator of nutritional condition. In many species, individuals in better body condition are also the ones that display more colorful plumage (Senar et al. 2003, 2008). For example, the width of tail growth bars, an indicator of nutritional status commonly used in avian studies, is positively correlated with the hue of the breast yellow coloration in Great Tits (Senar et al. 2003). However, to the best of our knowledge, no studies have ever examined how variation of nutritional conditions may drive the within-individual increase of coloration observed in many passerine species.

To fill this gap, we performed a longitudinal study in Great Tits where we used tail ptilochronology to estimate nutritional condition experienced by the same birds, during feather growth (Carrascal et al. 1998) as yearling and then as adult, in order to assess how a potential increase of nutritional condition in adult individuals may be associated with the increase of carotenoid-based coloration measured in these individuals.

\section{Methods}

Field methods

From 1997 to 2005, funnel traps baited with husked peanuts were used to capture 38 male Great Tits (as yearling and then as adult) in our study population near Barcelona, northeast Spain $\left(41^{\circ} 28^{\prime} \mathrm{N}, 2^{\circ} 09^{\prime} \mathrm{E}\right)$. At capture, each bird was leg-banded with a numbered aluminum ring for individual identification. Age of birds was determined (as yearling-EURING ages 3 and 5; or as adult-EURING ages 4 and 6) according to Jenni and Winkler (1994). Finally, the right and left fifth rectrices (R5) were plucked, and the birds were then released at the trapping site.

\section{Ptilochronology}

Methods to measure feather growth bar width follow those described in Carrascal et al. (1998). Briefly, for each feather, the width of the ten first visible growth bars (starting from the distal part) was measured. Two entomological pins were inserted through the feather in order to mark the distal and the proximal ends of each growth bars on a piece of polyspan. The distance between the two marks was then measured with a caliper $(0.01 \mathrm{~mm})$ and the average growth bar width was calculated for each feather, giving an estimation of the rate of feather growth per day. A subsample of 10 feathers was measured twice in order to compute repeatability, which was high and significant $\left(r_{\mathrm{i}}=0.97 ; P=0.01\right)$. The average of the two collected feathers from each individual was used for the analyses.

\section{Plumage coloration}

A portable colorimeter Minolta CR200 (Minolta 1994) was used to obtain hue, chroma and lightness of the breast yellow plumage. Hue corresponds to wavelength, which may be considered as the color tone (expressed in degrees). For the Great Tits' yellow breast coloration, low hue values correspond to a more orange tone, whereas high values correspond to a greenish tone. Chroma measures the color purity in a continuous scale ranging from 0 to 100 . Lightness measure the light intensity of the yellow coloration and is also expressed in a continuous scale from 0 to 100 . Color measurements were taken at $90^{\circ}$, making contact with the surface of the feathers patch. We made three measurements of the yellow patch to obtain a reliable mean of male breast coloration. Repeatability of these measures was high $\left(r_{\mathrm{i}}=0.85-0.92, P<0.001\right)$ (Figuerola et al. 1999).

\section{Statistics}

We performed repeated measures ANOVAs with the growth bars width and the color data collected on yearling and adult as variables to explain and with age as within-subject factors. Lightness, hue and chroma values were standardized with GLM for the year of trapping and for a potential effect of color abrasion (days from 1 October), adding the residual value to the population mean (Figuerola and Senar 2005). In addition, the growth bars width data of both yearling and adult birds were standardized for the year of trapping, also using GLM. All statistical analyses were performed with Statistica 6.0 and data were considered significant at the 0.05 level.

\section{Results}

We found that hue $\left(F_{1,37}=4.8, P=0.03\right)$ and chroma $\left(F_{1,37}=17.5, P=0.001\right)$ increased with age (paired data). However, lightness $\left(F_{1,37}=0.7, P=0.40\right)$ and growth bar width $\left(F_{1,37}=0.004, P=0.95\right)$ were not significantly different between yearling versus adult birds (paired data).

\section{Discussion}

In previous studies, we showed that (1) older male Great Tits are in general greener and more saturated in color than 
yearling individuals (i.e. higher hue and chroma) (Del Val et al. 2010), and (2) the hue of the breast carotenoid-based coloration is correlated with the nutritional condition as estimated by the rate of tail growth (Senar et al. 2003). Here, we confirm that adult birds are more colorful, and we examined how within-individual variation of nutritional status may explain this difference of carotenoid-based coloration observed between adult and yearling Great Tits. We showed that nutritional condition (repeated measurements of tail growth) was not significantly different between yearling and adult individuals, strongly suggesting that the increase in plumage coloration is not due to a general increase in foraging efficiency (foraging efficiency being defined as the ability to find food independently of its quality) with age (e.g., Desrochers 1992). Instead, our study implicates other behavioural and/or ecophysiological factors that drive yearling/adult differences in plumage coloration.

First, the molt timing is different in adult (early or midsummer) and yearling birds (late summer; Cramp and Perrins 1993). Thus, seasonal differences in the dietary availability of carotenoids (e.g., types and quantity of caterpillars, insects, seeds, etc.) in early and late summer may explain the increase of plumage coloration with age (Del Val et al. 2010). In addition, Hartley and Kennedy (2004) have proposed that the carotenoid-based coloration might better reveal the levels of other antioxidant compounds which can protect carotenoids from oxidation and bleaching. Thus, seasonal variation in the dietary availability of these other dietary antioxidants may also be an important driver of the increase of coloration observed in adult birds. Second, a specific increase in the ability to search for key food sources such as carotenoids may also drive the difference of coloration observed. In accordance with this hypothesis, Senar et al. (2010) recently showed that adult Great Tits have a strong preference for carotenoid-enriched prey type in two experiments in the field and in captivity where birds had the choice between carotenoidrich and -poor mealworms which did not differ with respect to color, size or nutritional value. It would be now interesting to test if yearling individuals have already developed this ability to estimate the carotenoid content in prey. Third, yearling individuals may be exposed to higher levels of parasitism and/or oxidative stress, and the antioxidant carotenoids may be drained from body reserves in order to maintain an acceptable level of oxidative stress, at the expense of the plumage coloration. In accordance with this hypothesis, it was shown that adult Great Tits in Sweden had a lower mean intensity of infection by hematozoan parasites than yearling birds (Allander and Bennett 1994). In addition, parasitism seems to be one of the major factors influencing the development of the carotenoid-based coloration in this species (Hõrak et al. 2001).
Finally, plumage color differences between yearling and adult Great Tits could be explained by physiological differences in the ability to extract and then assimilate dietary carotenoids (e.g., uptake and storage; McGraw and Parker 2006).

Future studies should examine for difference of nutritional condition between adult and yearling females and experimentally test for difference of carotenoid assimilation between adult and yearling individuals. In addition, an assessment of parasites, circulating carotenoids, antioxidants, and oxidative stress levels in adult and yearling birds should also constitute an important piece of information to understand the age-related variation of coloration in Great Tits.

Acknowledgments We thank Lluïsa Arroyo, Jordi Domènech, Jordi Figuerola, Javier Quesada, Iker Ruiz, Esther del Val, and all the students that have helped us during the years of the study. We also thank to the Gil family, owners of Can Catà field station, for their support in field work. This study was funded by CGL-2012-38262 research project to J.C.S. from the Ministry of Economy and Competitivity, Spanish Research Council. M.G. was supported by a Swiss FAN grant. Birds were handled with the permission of the Departament de Medi Ambient, Generalitat de Catalunya. Rings were provided by the Catalan Ringing Office (ICO).

\section{References}

Allander K, Bennett GF (1994) Prevalence and intensity of haematozoan infection in a population of Great Tits Parus major from Gotland, Sweden. J Avian Biol 25:69-74

Carrascal LM, Senar JC, Mozetich I, Uribe F, Domenech J (1998) Interactions among environmental stress, body condition, nutritional status, and dominance in Great Tits. Auk 115(3):727-738

Cramp S, Perrins CM (1993) The birds of the Western Palearctic, vol VII. Oxford University Press, Oxford

Del Val E, Quesada J, Senar JC (2010) Age-related differences in a carotenoid-based coloration trait are due to within-individual changes in Great Tits Parus major. Ardea 98:179-184

Delhey K, Kempenaers B (2006) Age differences in Blue Tit Parus caeruleus plumage colour: within-individual changes or colourbiased survival? J Avian Biol 37:339-348

Desrochers A (1992) Age and foraging success in European blackbirds: variation between and within individuals. Anim Behav 43:885-894

Figuerola J, Senar JC (2005) Seasonal changes in carotenoid- and melanin-based plumage coloration in the Great Tit Parus major. Ibis 147:797-802

Figuerola J, Pascual J, Senar JC (1999) The use of a colorimeter in field studies of Blue Tit Parus caeruleus coloration. Ardea 87:269-275

Hartley RC, Kennedy MW (2004) Are carotenoids a red herring in sexual display? Trends Ecol Evol 19:353-354

Hõrak P, Ots I, Vellau H, Spottiswoode C, Møller AP (2001) Carotenoid-based plumage coloration reflects hemoparasite infection and local survival in breeding Great Tits. Oecologia 126:166-173

Jenni L, Winkler R (1994) Moult and ageing of European Passerines. Academic Press, London 
McGraw KJ, Parker RS (2006) A novel lipoprotein-mediated mechanism controlling sexual attractiveness in a colorful songbird. Physiol Behav 87:103-108

Pagani-Nuñez E, Senar JC (2012) Changes in carotenoid-based plumage colour in relation to age in European Serins Serinus serinus. Ibis 154:155-160

Senar JC, Figuerola J, Domènech J (2003) Plumage coloration and nutritional condition in the Great Tit Parus major: the roles of carotenoids and melanins differ. Naturwissenschaften 90:234-237
Senar JC, Negro JJ, Quesada J, Ruiz I, Garrido J (2008) Two pieces of information in a single trait? The yellow breast of the Great Tit reflects both pigment acquisition and body condition. Behaviour 145:1195-1210

Senar JC, Møller AP, Ruiz I, Negro JJ, Broggi J, Hohtola E (2010) Specific appetite for carotenoids in a colorful bird. PLOS ONE 5(5):e10716 